Journal of Applied Pharmaceutical Science Vol. 5 (10), pp. 048-051, October, 2015

Available online at http://www.japsonline.com

DOI: $10.7324 / \mathrm{JAPS} .2015 .501009$

ISSN 2231-3354 (cc) BY-NC-SA

\title{
Molecular characterization of genes encoding AmpC beta-lactamases in clinical isolates of Pseudomonas and Acinetobacter species
}

\author{
Sana Jamali*, Mohd. Shahid, Sobia Farrukh, Anuradha Singh, Haris M. Khan \\ Department of Microbiology, J.N.Medical College, Aligarh (U.P.), India.
}

\begin{tabular}{|c|c|}
\hline ARTICLE INFO & ABSTRACT \\
\hline $\begin{array}{l}\text { Article history: } \\
\text { Received on: } 07 / 07 / 2015 \\
\text { Revised on: } 21 / 07 / 2015 \\
\text { Accepted on: } 09 / 08 / 2015 \\
\text { Available online: } 28 / 10 / 2015\end{array}$ & $\begin{array}{l}\text { Emergence of AmpC beta-lactamases in isolates of Pseudomonas and Acinetobacter species, is a threatening } \\
\text { condition as they mediate resistance to a wide variety of } \beta \text {-lactam drugs, including } \alpha \text {-methoxy- } \beta \text {-lactams, such as } \\
\text { cefoxitin, narrow-, expanded- and broad-spectrum cephalosporins, aztreonam and are poorly inhibited by } \beta \text { - } \\
\text { lactam inhibitor combinations. The present study was conducted to determine the occurrence of bla } a_{\text {ampC }} \text { genes in } \\
\text { these pathogenic non-fermenters for their rapid and accurate detection. Monoplex PCR was done to detect bla } a_{a m p C}\end{array}$ \\
\hline $\begin{array}{l}\text { Key words: } \\
\text { bla } a_{\mathrm{ampC}} \text { Pseudomonas, } \\
\text { Acinetobacter. }\end{array}$ & $\begin{array}{l}\text { the third-generation cephalosporin and cefoxitin. Multiplex PCR assay was carried out to identify family-specific } \\
\text { AmpC beta-lactamase genes within Pseudomonas and Acinetobacter spp. PCR detected bla } a_{\mathrm{ampC}} \text { in } 43.24 \% \text { of } \\
\text { Pseudomonas and } 33.33 \% \text { of Acinetobacter isolates. Overall } 42.50 \% \text { of the total isolates were found to harbour } \\
\text { bla } a_{\mathrm{ampC}} \text { genes by PCR. By multiplex PCR, total eight }(20 \%) \text { isolates yielded a positive amplicon with AmpC- } \\
\text { specific primers. High prevalence of bla } a_{\mathrm{ampC}} \text { genes in cefoxitin-resistant isolates of Pseudomonas and } \\
\text { Acinetobacter isolates emphasizes that molecular detection methods should be carried out to know the exact } \\
\text { prevalence of beta-lactamases. }\end{array}$ \\
\hline
\end{tabular}

\section{INTRODUCTION}

Antibiotic resistance is now a linked global problem. It increases the morbidity, mortality and costs of treating infectious diseases. The threat from resistance (particularly multiple resistance in bacterial strains that have disseminated widely) has never been so great; however there are recent concerns about the increasing frequency of antibiotic resistance. The key factors driving this threat are increased antibiotic usage (in both human and animal medicine), greater movement of people and increased industrialization. The major forces behind the development of resistance in bacteria are exposure to antibiotics followed by selection and dissemination of resistant strains. The health care setting provides a favorable environment in this context. Resistant strains evolve and disseminate by direct and indirect contacts, where large numbers of people are congregated under one roof and where the usage of antibiotics is high. Therapeutic

\footnotetext{
* Corresponding Author

Dr. Sana Jamali, M.B.B.S., M.D., Department of Microbiology, J.N.Medical College, Aligarh (U.P), India \& Assistant Professor, Department of Microbiology, Integral Institute of Medical Sciences and research, Lucknow (U.P), India. Email: jamalisana@yahoo.com
}

options for infections caused by nosocomial isolates of Pseudomonas aeruginosa and Acinetobacter spp., expressing plasmid-mediated AmpC beta-lactamases are limited as these organisms are usually resistant to all beta-lactams except cefepime, cefpirome and carbapenams. Therefore, infection by these nosocomial isolates adversely affects clinical outcomes and patient treatment costs (Harris et al. 1999; Aloush et al. 2006). Since the information on the molecular documentation of $\mathrm{AmpC} \beta$ lactamases among Pseudomonas and Acinetobacter spp. are fragmentary in India; this study was carried to determine occurrence of $b l a_{\mathrm{ampC}}$ genes in these pathogenic non-fermenters for their accurate detection.

\section{MATERIALS AND METHODS}

The present prospective study was conducted in the department of Microbiology, J. N. Medical College, Aligarh Muslim University, Aligarh, during a period of one year (October 2010 to September 2011). Various clinical specimens received for routine culture and susceptibility testing in the clinical microbiology lab was studied. Clinical samples received in the laboratory were inoculated on the blood agar plate (BA) and teepol lactose agar (TLA) and then incubated overnight at $37^{\circ} \mathrm{C}$. 
Pseudomonas and Acinetobacter spp were identified by different microbiologcal methods. Antibiotic susceptibility testing was done. $30 \mu \mathrm{g}$ cefoxitin disc was used for initial screening of AmpC beta-lactamase production. A total of forty isolates (23 Pseudomonas and 17 Acinetobacter spp.), that were found resistant to any of the third-generation cephalosporin and cefoxitin were randomly selected for molecular characterization.

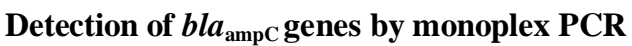

The study isolates were subjected to PCR as described by Feria et al., (2002) with some modifications to detect $b l a_{\mathrm{ampC}}$ genes. AmpC-F-5'-CCCCGCTTATAGAGCAACAA-3' (634bp) and AmpC-R-5'-TCAATGGTCGACTTCACACC -3' primers were used. The reaction mixture was placed in MJ-mini Bio-Rad thermal cycler (Bio-Rad, USA). The PCR amplification cycle was performed with cycling conditions consisting of an initial denaturation step at $95^{\circ} \mathrm{C}$ for $15 \mathrm{~min}$, followed by 35 cycles of $94^{\circ} \mathrm{C}$ for $60 \mathrm{sec}$., $58^{\circ} \mathrm{C}$ for $2 \mathrm{~min}$., $72^{\circ} \mathrm{C}$ for $3 \mathrm{~min}$. and the process was completed with a final elongation step at $72^{\circ} \mathrm{C}$ for $10 \mathrm{~min}$. Amplified PCR products were analysed by gel electrophoresis with $2 \%$ agarose (Bangalore Genei, India) gel containing ethidium bromide. After electrophoresis DNA fragments were visualized by Bio-Rad Gel documentation system (Bio-Rad, USA). Previously characterized isolates provided by Prof. Daniel Jonas, Germany, were used as positive controls.

\section{Detection of plasmid-mediated AmpC $\beta$-lactamase by multiplex PCR}

Multiplex PCR was carried out to detect family-specific plasmid-mediated AmpC $\beta$-lactamase genes by implementing protocol as described by Perez-Perez and Hanson (2002). The total volume of reaction mixture was $25 \mu$ l (Table 1). Primers were synthesised by Operon Biotechnologies, Cologne, Germany.

\section{RESULTS AND DISCUSSION}

As it is very crucial to know the exact prevalence of AmpC beta-lactamase harboring isolates of Pseudomonas and Acinetobacter spp., these isolates were subjected to genotypic detection by PCR. Table 2 shows that monoplex PCR detected bla $_{\mathrm{ampC}}$ in $43.24 \%$ of Pseudomonas and $33.33 \%$ of Acinetobacter isolates. Overall $42.50 \%$ of the total isolates were found to harbour $b l a_{\text {ampC }}$ genes by monoplex PCR (Figure 1). Multiplex PCR assay was carried out to identify family-specific AmpC beta-lactamase genes within Pseudomonas and Acinetobacter spp. As shown in table 2, total eight $(20 \%)$ isolates yielded a positive amplicon with AmpC-specific primers.

Five isolates, out of total eight positive isolates corresponded to the MOX-family, while only one isolate belonged to CIT-family. Rest 2 isolates were confirmed to be of FOXfamily. Two distinct bands were noticed in only one isolate, which belonged to the genus Pseudomonas. In the isolate showing two bands in multiplex PCR, the upper band corresponded to the CIT family and the lower band was obtained at 200bp, which corresponds to the expected position of the FOX family (Figure 2). To identify the exact family to which lower band belongs, monoplex PCR was done for all the families of AmpC $\beta$ lactamases and an amplified product corresponding to EBC family was obtained.

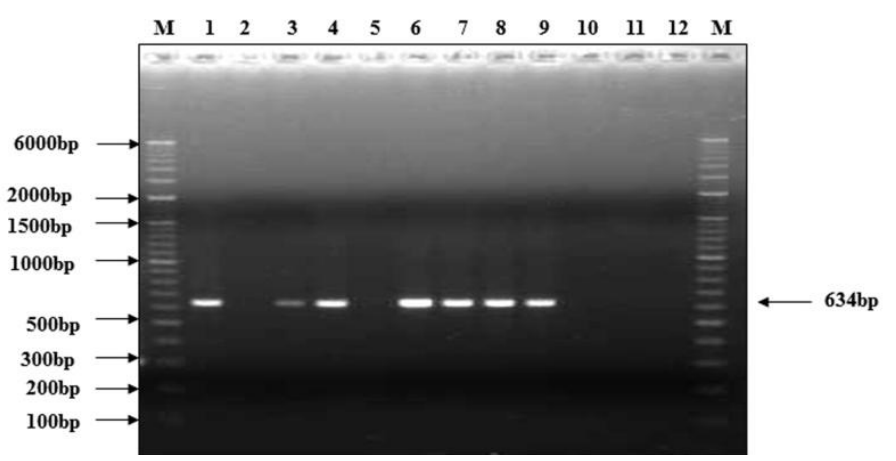

Fig. 1: 2\% agarose gel is showing amplification pattern of $b l a_{\text {ampc }}$ genes. Lanes $\mathrm{M}$ are showing Fermentas high range DNA ruler. Lane 1 shows positive control strain for $b l a_{\mathrm{ampc}}$, while lane 2 shows negative control. Lanes 3, 4, 6-9 shows clinical isolates harbouring $b l a_{\text {ampc }}$ genes, while lanes 10-12 shows negative isolates.

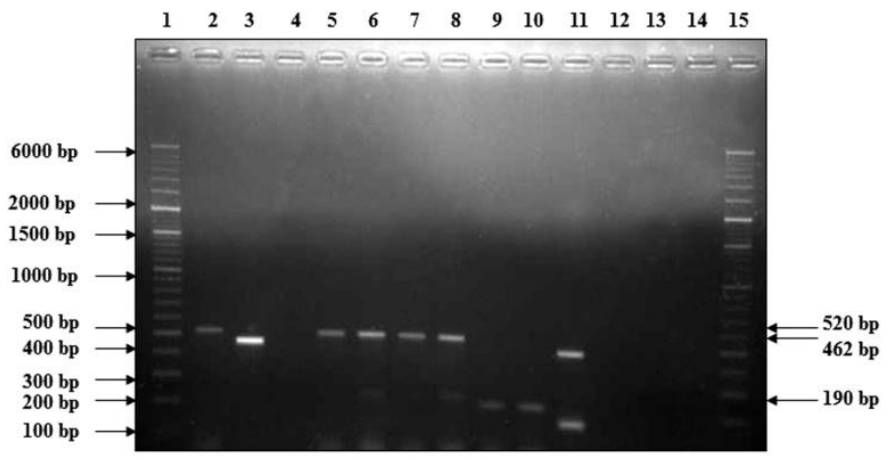

Fig. 2: Electrophoretogram (on 2\% agarose) showing results of multiplex PCR for the detection of blaampC alleles. Lanes 1 and 15 show ladders (Fermentas high range DNA ruler). Lane 3 shows positive control of CIT family, whereas lane 4 shows negative control. Lanes 5-8 shows amplicons of MOX family in test strains. Lanes 9 and 10 shows FOX-family in test strains. Lane 11 shows test isolate possessing both CIT and EBC family. Lanes 12-14 shows negative isolates.

Apart from fragmentary reports regarding the prevalence of AmpC beta-lactamases in Pseudomonas and Acinetobacter spp, the actual prevalence is still unknown, as most of these studies are based on phenotypic detection methods only. One important fact is that, there is currently no clear consensus regarding guidelines for phenotypic screening or confirmatory tests for AmpC $\beta$-lactamaseproducing organisms (Shahid et al., 2004). Our study reveals high prevalence of $b l a_{\mathrm{ampC}}(42.50 \%)$ among clinically important Pseudomonas and Acinetobacter isolates from our centre. In contrary to our results, from North India, $20 \%$ of $P$. aeruginosa (Delhi) and $20.7 \%$ of Gram-negative organisms (Aligarh) and $47.8 \%$ E. coli, $17.3 \%$ P. aeruginosa, $13 \%$ K. pneumoniae (Kolkata) were reported as AmpC $\beta$-lactamase producers (Manchanda and Singh, 2003; Shahid et al., 2003; Suranjana and Manjusri, 2005). 37.50\% isolates have been reported as AmpCproducers from Chennai (Subha et al., 2003). 
Table 1: Preparation of reaction mixture for detection of plasmid-mediated AmpC $\beta$-lactamases.

\begin{tabular}{|c|c|}
\hline Reagents & Quantity $(\mu \mathrm{l})$, for $25 \mu \mathrm{l}$ of reaction mixture \\
\hline \multicolumn{2}{|l|}{$\begin{array}{c}\text { Primers } \\
\end{array}$} \\
\hline 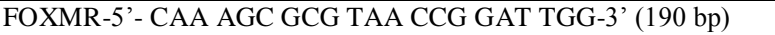 & 0.16 \\
\hline FOXMF-5' - AAC ATG GGG TAT CAG GGA GAT G-3' & 0.16 \\
\hline EBCMR-5’'- CTT CCA CTG CGG CTG CCA GTT-3’ (302 bp) & 0.20 \\
\hline EBCMF-5’'- TCG GTA AAG CCG ATG TTG CGG-3' & 0.20 \\
\hline ACCMR-5'- TTC GCC GCA ATC ATC CCT AGC-3' (346 bp) & 0.20 \\
\hline ACCMF-5’- AAC AGC CTC AGC AGC CGG TTA-3' & 0.20 \\
\hline DHAMR-5' - CCG TAC GCA TAC TGG CTT TGC-3' (405 bp) & 0.24 \\
\hline DHAMF-5'- AAC TTT CAC AGG TGT GCT GGG T-3' & 0.24 \\
\hline CITMRb-5'-TTT CTC CTG AAC GTG GCT GGC-3’ (462 bp) & 0.24 \\
\hline CITMF-5'-TGG CCA GAA CTG ACA GGC AAA-3' & 0.24 \\
\hline MOXMR-5'- CAC ATT GAC ATA GGT GTG GTG C-3' (520 bp) & 0.24 \\
\hline MOXMF-5'-GCT GCT CAA GGA GCA CAG GAT-3' & 0.24 \\
\hline PCR master mixture & 12.5 \\
\hline Template DNA solution & 2.5 \\
\hline Water, nuclease free & 7.44 \\
\hline
\end{tabular}

$\mathrm{F}$ denotes forward primer, $\mathrm{R}$ denotes reverse primer

Table 2: bla $_{\text {ampC }}$ Detection by monoplex and multiplex PCR.

\begin{tabular}{|c|c|c|c|c|}
\hline \multirow[t]{2}{*}{ Organism } & \multicolumn{2}{|c|}{ Monoplex PCR } & \multicolumn{2}{|c|}{ Multiplex PCR } \\
\hline & Positive & Negative & Positive & Negative \\
\hline Pseudomonas spp. $(\mathrm{n}=37)$ & $16(43.24 \%)$ & $21(56.76 \%)$ & $8(21.67 \%)$ & $29(78.38 \%)$ \\
\hline Acinetobacter spp. $(\mathrm{n}=3)$ & $1(33.33 \%)$ & $2(66.67 \%)$ & 0 & $3(100 \%)$ \\
\hline Total $(n=40)$ & $17(42.50 \%)$ & $23(57.50 \%)$ & $8(20 \%)$ & $32(80 \%)$ \\
\hline
\end{tabular}

In another study performed by Singhal et al. (2005), prevalence of AmpC $\beta$-lactamases was reported as $8 \%$, which is much lower than our finding in Pseudomonas and Acinetobacter spp. In 2007, Hemlatha et al., from Chennai reported 47.3\% AmpC-producers in Escherichia coli and Klebsiella isolates. In 2010, Upadhyay et al., from Varanasi, reported $59.4 \%$ isolates of P. aeruginosa as AmpC-producers. In the same year, Mohamudha et al. (2010), reported 93.6\% Gram-negative clinical isolates as AmpC-producers, based on three-dimensional extract method. They reported $66.6 \%$ and $55.5 \%$ plasmid-mediated AmpCproducers in Acinetobacter and Pseudomonas respectively. 33 (32.7\%) isolates of Pseudomonas aeruginosa were confirmed to be positive for AmpC beta-lactamase, in study conducted by kumar et al. in 2012.

Similar results were reported by Sreeshma et al. in 2013 where $48 \%$ of isolates were inducible AmpC producers and only $2 \%$ produced plasmid mediated AmpC beta-lactamase. Oteo et al., (2010) from Spain have reported the occurrence of plasmidmediated $b l a_{\text {ampc }}$ in $38 \%$ isolates. Tan et al. (2009) detected $b l a_{\text {ampc }}$ in $47 \%$ isolates. In a study carried out by Shahid et al. (2009) in Aligarh between 2003 and 2005, 39.1\% of isolates belonging to family Enterobacteriaceae, were found to carry $b l a_{\text {ampc }}$ genes. In a recent study conducted in Iran $60.8 \%$ of tha Pseudomonas aeruginosa isolates harbored $b l a_{\text {ampc }}$ (Roya et al., 2014).

\section{CONCLUSION}

The detection of $b l a_{\mathrm{ampC}}$ reflects the emergence of betalactamases among antimicrobial resistant Pseudomonas and Acinetobacter isolates. The present study also highlights that molecular methods should be carried out in clinical laboratories to know the accurate prevalence of beta-lactamases, so that effective steps can be taken to prevent the further spread of these resistant strains.

\section{REFERENCES}

Aloush V, Navon-Venezia S, Seigman-Igra Y, Cabili S, Carmeli Y. Multidrug-resistant Pseudomonas aeruginosa: risk factors and clinical impact. Antimicrob Agents Chemother, 2006; 50: 430-8.

Feria C, Ferreira E, Correia JD, Goncalves J, Canica M. Patterns and mechanisms of resistance to beta-lactams and beta-lactamase inhibitors in uropathogenic Escherichia coli isolated from dogs in Portugal. J Antimicrob Chemother, 2002; 49: 77-85.

Harris A, Torres-Viera C, Venkataraman L, DeGirolami P, Samore M, Carmeli Y. Epidemiology and clinical outcomes of patients with multi-resistant Pseudomonas aeruginosa. Clin Infect Dis, 1999; 28:1128-33

Hemlatha V, Padma M, Sekar U, Vinodh TM, Arunkumar AS. Detection of AmpC beta lactamases production in Escherichia coli \& Klebsiella by an inhibitor based method. Indian J Med Res, 2007; 126:220-3.

Kumar V, Sen MR, Nigam C, Gahlot R, Kumari S. Burden of different beta-lactamase classes among clinical isolates of AmpC-producing Pseudomonas aeruginosa in burn patients: A prospective study. Indian J Crit Care Med, 2012; 16:136-40.

Manchanda V, Singh NP. Occurrence and detection of AmpC beta-lactamases among Gram-negative clinical isolates using a modified three-dimensional test at Guru Tegh Bahadur Hospital, Delhi, India. J Antimicrob Chemother, 2003; 51:415-8.

Mohamudha PR, Harish BN, Parija SC. AmpC beta-lactamases among gram-negative clinical isolates from a tertiary hospital, South India. Braz J Microbiol, 2010; 41:596-602.

Oteo J, Cercenado E, Cuevas O, Bautista V, Delgado-Iribarren A, Orden B et al. AmpC beta-lactamases in Escherichia coli: emergence of CMY-2-producing virulent phylogroup D isolates belonging mainly to STs $57,115,354,393$, and 420 , and phylogroup B2 isolates belonging to the international clone O25b-ST131. Diagn Microbiol Infect Dis, 2010; 67:270-6.

Perez-Perez FJ and Hanson ND. Detection of plasmid-mediated AmpC $\beta$-lactamase genes in clinical isolates by using multiplex PCR. J Clin Microbiol, 2002; 40: 2153-62. 
Roya R, Fereshteh E, Seyyed AT, Dariush MT. Prevalence of Extended-Spectrum and Metallo $\beta$-Lactamase Production in AmpC $\beta$ Lactamase Producing Pseudomonas aeruginosa Isolates From Burns. Jundishapur J Microbiol, 2014. 7: 16436

Shahid M, Ensor VM, Hawkey PM. Emergence and dissemination of Enterobacteriaceae with plasmid-mediated CMY-6 and CTX-M-15 beta-lactamases in community in North-India. World J Microbiol Biotechnol, 2009; 25:1439-46.

Shahid M, Malik A, Agrawal M, Singhal S. Phenotypic detection of the extended-spectrum and AmpC beta-lactamases by a new spot-inoculation method and modified three-dimensional extract test: comparison with the conventional three-dimensional extract test. J Antimicrob Chemother, 2004; 54:684-7.

Shahid M, Malik A, Sheeba. Multidrug-resistant Pseudomonas aeruginosa strains harbouring R-plasmids and AmpC beta-lactamases isolated from hospitalised burn patients in a tertiary care hospital of North India. FEMS Microbiol Lett, 2003; 228:181-6.

Singhal S, Mathur T, Khan S, Upadhyay DJ, Chugh S, Gaind R. Evaluation of methods for AmpC beta-lactamase in Gram negative clinical isolates from tertiary care hospitals. Ind J Med Microbiol, 2005; 23:120-4.

Sreeshma P, Champa H, Sunil RP, Subbannayya K. Detection of extended spectrum $\beta$-lactamase, AmpC $\beta$-lactamase and metallo $\beta$ lactamase in clinical isolates of Pseudomonas aeruginosa. J Pharm Biomed Sci, 2013; 33:1506-15.
Subha A, Devi VR, Ananthan S. AmpC beta-lactamase producing multidrug resistant strains of Klebsiella spp. \& Eschericia coli isolated from children under five in Chennai. Indian J Med Res, 2003; 117:13-8.

Suranjana A, Manjusri B. AmpC $\beta$-lactamase producing bacterial isolates from Kolkata Hospital. Indian J Med Res, 2005; 122: 224-33.

Tan TY, Ng LS, He J, Koh TH, Hsu LY. Evaluation of screening methods to detect plasmid-mediated AmpC in Escherichia coli, Klebsiella pneumoniae, and Proteus mirabilis. Antimicrob Agents Chemother, 2009; 53:146-9.

Upadhyay S, Sen MR, Bhattacharjee A. Presence of different beta-lactamase classes among clinical isolates of Pseudomonas aeruginosa expressing AmpC beta-lactamase enzyme. J Infect Dev Ctries, 2010; 4:239-42.

\section{How to cite this article:}

Sana Jamali, Mohd. Shahid, Sobia Farrukh, Anuradha Singh, Haris M. Khan. Molecular characterization of genes encoding AmpC beta-lactamases in clinical isolates of Pseudomonas and Acinetobacter species. J App Pharm Sci, 2015; 5 (10): 048-051. 